\title{
Machine Vision Condition Monitoring of Heavy-Haul Railcar Structural Underframe Components
}

\author{
Bryan W. Schlake ${ }^{1}$, John R. Edwards ${ }^{1}$, John M. Hart ${ }^{2}$, \\ Christopher P.L. Barkan ${ }^{1}$, Sinisa Todorovic ${ }^{2}$, and Narendra Ahuja ${ }^{2}$ \\ ${ }^{1}$ Railroad Engineering Program - Department of Civil and Environmental Engineering \\ ${ }^{2}$ Computer Vision and Robotics Laboratory - Department of Electrical and Computer Engineering \\ University of Illinois at Urbana-Champaign
}

\begin{abstract}
Summary: Monitoring the structural health of heavy-haul rolling stock is critical to ensuring safe and efficient railroad operation. As a result, periodic manual inspections are required to detect structural damage and defects. These inspections rely heavily on the acuity, knowledge and endurance of qualified inspection personnel. There is the potential to enhance inspection effectiveness and efficiency through machine vision technology, which uses computer algorithms to convert digital image data into useful information. This paper describes research and development of an automated machine vision inspection system capable of detecting structural defects in freight car underframes.
\end{abstract}

Index Terms: multiscale segmentation, computer vision, predictive maintenance, center sill, wagon

\section{INTRODUCTION}

United States Federal Railroad Administration (FRA) regulations require that every car placed in a train must be inspected by a car inspector or train crew member before departing a yard or terminal. The current railcar inspection process is tedious, labor intensive, and relies on personnel with varied experience and training, performing their task under a wide range of environmental conditions. Additionally, there exists no practical means of recording and retaining inspection information unless a billable repair is required. This makes it difficult to track a car's condition over time or perform trend analyses. As a result, the majority of railcar maintenance is reactive, resulting in less efficient repair and maintenance processes.
Consequently, the Association of American Railroads (AAR) and the Transportation Technology Center, Inc. (TTCI) initiated a program to develop and implement automated inspection technologies, called Technology Driven Train Inspection (TDTI).

\subsection{Technology Driven Train Inspection}

The goal of TDTI is to provide safer, more efficient, and traceable means of rolling stock inspection by automating the mechanical inspection process through a variety of technologies [3]. Examples of these technologies include the automated inspection of railcar truck components, safety appliances and passenger car undercarriages $[4,5,6]$. The ultimate vision of TDTI is a network of 
automatic wayside systems capable of inspecting and monitoring the North American freight car fleet in order to maintain compliance with FRA regulations and railroad-specific maintenance and operational standards. To reach this goal, the final wayside inspection systems must be comprehensive in scope, inspecting all aspects of the car. As a result, TDTI has initiated the development of separate automated inspection technologies that will address each aspect of the federally-mandated freight car inspection requirements. One aspect of the TDTI initiative is the development of the system known as Automated Inspection of Structural Components (AISC), which will use cameras and computer algorithms to aid in the inspection of freight car underbodies.

\subsection{Structural Underframe Components}

Structural underframe components contribute to the structural integrity of the railcar by supporting the car body and lading and transmitting longitudinal buff and draft forces. The primary structural component, the center sill, runs longitudinally along the center of the car, forming the backbone of the underframe and transmitting the majority of buff and draft forces through the car [1]. Several other structural components are also critical to load transfer, including the sidesills, body bolsters, and crossbearers. The sidesills are longitudinal members, similar to the center sill, running along the entire length of the car on either side. Body bolsters are transverse members near each end of the car that transfer the car's load from the car body to the trucks. Crossbearers and crossties are transverse members that connect the sidesills to the center sill and help distribute the load between the longitudinal members of the car. These components work together as a system to help maintain the car's camber and structural integrity. Each of these components must be regularly inspected to ensure the safe and efficient operation of rolling stock.
FRA Mechanical Regulations require the inspection of center sills for breaks, cracks, and buckling, and the inspection of sidesills, crossbearers, and body bolsters for breaks [2]. To effectively detect structural defects, a car inspector must walk around the entire car, looking beneath it with the aid of a flashlight to view each structural component. Due to time constraints associated with typical pre-departure mechanical inspections, cars are inspected with this level of scrutiny only before undergoing major repairs in a car shop. To address these concerns, the AAR and TTCI proposed using machine vision technology, in the AISC system, to inspect underframe components.

\subsection{Machine Vision Technology}

A machine vision system acquires data using digital cameras, organizes and analyzes the images using computer algorithms, and produces useful information, such as the type and location of defects. The machine vision algorithms use visual cues to locate areas of interest on the freight car and then analyze each component to determine its variance from the baseline case. AISC will work collectively with other automated inspection systems to inspect freight cars efficiently and objectively and will also maintain historical health records for each car that undergoes inspection. Maintaining these records will allow potential structural defects to be monitored over time so that components are repaired prior to failure. Applying these new technologies to the inspection process has the potential to enhance rolling stock maintenance efficiency and safety.

\subsection{Condition Based Maintenance}

A primary benefit of AISC and other automated inspection systems is the facilitation of predictive, or condition-based, maintenance. Condition-based maintenance involves the monitoring of certain parameters related to 
component health or degradation and the subsequent corrective actions taken prior to component failure [7]. Instead of taking advantage of condition-based maintenance, current structural component inspection and repair practices rely on corrective maintenance, which occurs only after a critical defect is detected. This approach maximizes component service life but makes repair planning difficult. Furthermore, when repairs are needed, they can disrupt service, leading to higher expenses and reduced efficiency. Railroads have recognized the advantage of predictive maintenance and have begun implementing other technologies similar to AISC that monitor subtle indicators of railcar component health (e.g. Truck Performance Detectors and the AAR's Fully Automated Car Train Inspection System FactIS $\left.^{\mathrm{TM}}\right)$ [8].

\section{REGULATORY COMPLIANCE}

According to Section 215.121 of Title 49 in the U.S. Code of Federal Regulations (CFR), structural underframe components must be inspected on each railcar placed in a train [2]. The specific regulations pertaining to freight car bodies form the basis for determining which components will be inspected by AISC. According to the regulations, the center sill may not be broken, cracked more than 6 inches, or bent/buckled more than 2.5 inches in any 6 foot length. Specific parameters are also established for the allowable magnitude of cracks and buckling because these defects may undermine the integrity of the sill, resulting in a center sill failure [9]. Fines assessed by FRA inspectors for a broken center sill are among the highest in CFR 215.121, matched only by violations due to loose or broken axles.

Inspection data from the FRA Office of Safety from 2000 to 2007 shows that on average $59 \%$ of structural component defects are comprised of broken, cracked, bent, or buckled center sills
(CS), while the remaining $41 \%$ represent defective sidesills (SS), body bolsters (BB), or crossbearers (CB) (Figure 1). Based on these data and guidance from the AAR, the primary focus of AISC is inspecting the center sill and the secondary focus is the inspection of other structural components. All these components, although infrequently defective, are critical to the structural integrity of the freight car.

\section{Average Defects Per Year (2000-2007)}

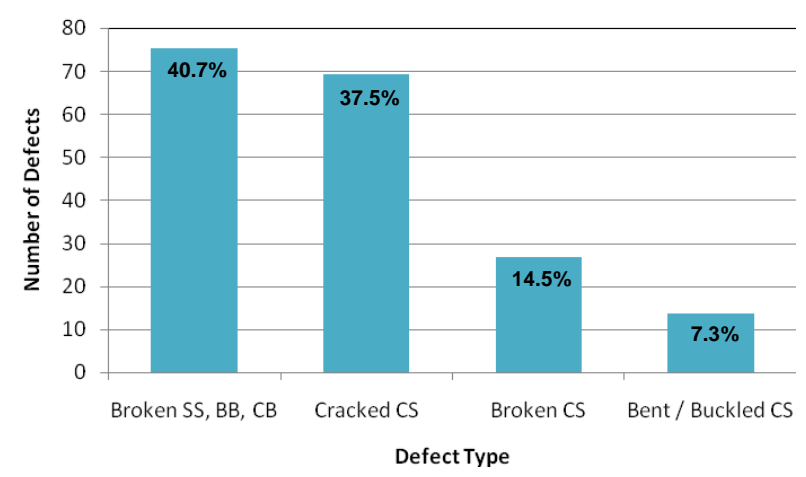

Figure 1: Average number of structural defects recorded by FRA Motive Power and Equipment inspectors per year

\section{BACKGROUND}

Previous research at UIUC has demonstrated the feasibility of using machine vision to detect defects and other anomalies on the underbodies of passenger cars and locomotives [6]. Algorithms using both the visible and infrared spectra demonstrated that missing, damaged, or overheated components could be detected as well as incipient failures and foreign objects beneath the cars. Videos of in-service trains were recorded as they moved over a stationary camera mounted in a pit beneath the tracks. The combination of information from both the thermal and visible spectra identified certain defects that might otherwise go unnoticed by human inspectors. This research addressed the difficulties of acquiring images from beneath a railcar: an inherently challenging location due to lighting requirements, space constraints, and the difficulties involved in protecting the equipment. 
Another machine vision system was developed to inspect railcar truck components using wayside cameras and a perpendicular view of the truck [4]. Computer algorithms were developed to detect the locations of brake components, spring sets, and bearing end cap bolts. This work laid the groundwork for developing additional automated freight car inspection systems using machine vision, such as the Automated Safety Appliance Inspection System (ASAIS) [5]. ASAIS detects deformed ladders, handholds, and brake wheels, using visual learning techniques to determine the difference between FRA defects needing immediate attention and deformations that are less critical. The results and methods developed in these projects have been incorporated into other aspects of the AAR's TDTI program, and knowledge gained from these research initiatives was applied to inspecting the underbody of freight rolling stock in the current project.

\section{METHODOLOGY}

The goal of the work done at UIUC was to demonstrate the feasibility of AISC. The initial stages of this project focused largely on collecting images of representative railcar structural components. Using computer algorithms, these images were converted from raw video data into full panoramas of the railcar underbody. Subsequent algorithms and approaches were developed to analyze the panoramas, detect components of interest, and locate defects.

\subsection{Preliminary Image Acquisition}

Initial tests were conducted at the Monticello Railway Museum in Monticello, IL on an Illinois Central, 1950 era AAR-standard-design hopper car. The car was rolled over a locomotive repair pit while recording videos using various lighting arrangements (Figure 2).



(a)

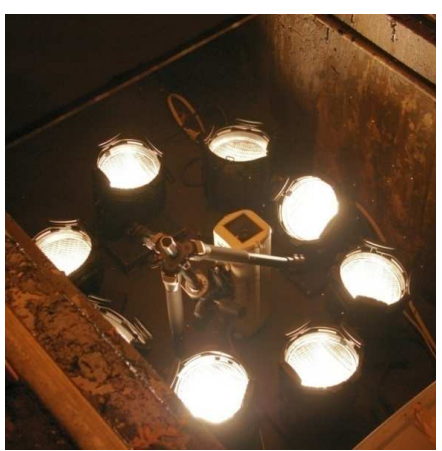

(b)
Figure 2: Experimental set-up at Monticello (a); lighting and camera arrangement in the pit (b)

The camera and lighting arrangement was placed at the bottom of the three-foot pit, and data were acquired via a laptop computer adjacent to the tracks. Videos were taken at varying train speeds and lighting conditions, and a panoramic image was developed from the video data (Figure 3).

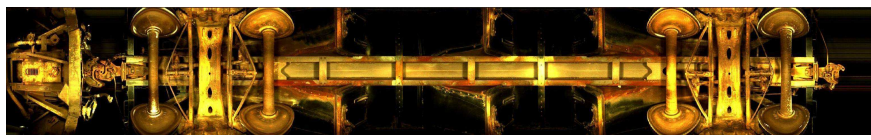

Figure 3: Panoramic image of hopper car underbody using preliminary image acquisition methods

This image provided initial confidence in the feasibility of this method of automated structural component inspection, because the structural components including the center sill and crossbearers were clearly visible. Many mechanical components are also visible in the panorama including the couplers, much of the draft gear, the truck bolsters, the brake rigging, brake beam, the interior springs in each spring nest, and the axles. Initial data acquisition efforts verified the feasibility of capturing structural components of interest and provided a basis for properly illuminating the railcar underbody.

\subsection{Data Collection}

After analyzing the preliminary image acquisition results and subsequent data collected using portable image acquisition carts, an 
experimental set-up was developed (Figure 4) and data collection procedures were defined.



Figure 4: Equipment set-up showing $90^{\circ}$ straight-up view

This equipment arrangement was used during testing at a Norfolk Southern locomotive repair facility in Decatur, IL (Figure 5).

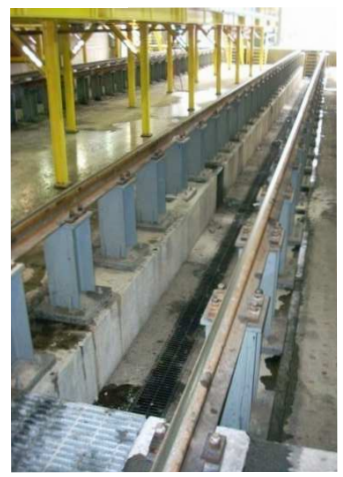

(a)

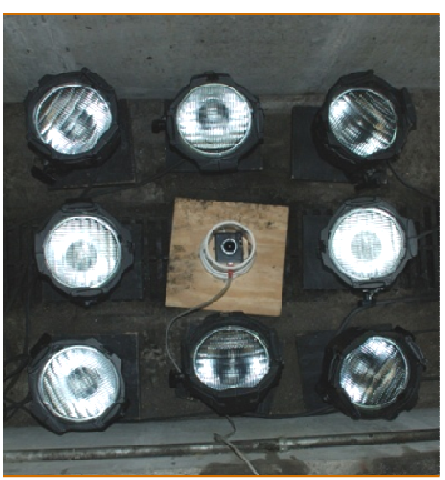

(b)
Tests were run on several different railcars by rolling them above the camera at 3-5 mph. As before, the videos were developed into panoramic images (Figure 6). Results from the testing at Decatur show much more even illumination for the hopper car image (Figure 6a) as compared to the previous hopper panorama (Figure 3). Only the center strip of each individual video frame is extracted to develop the panorama, so improvements were made by focusing illumination at the center of the image. The panorama of the gondola underbody (Figure 6b) provides a clear view of the center sill, crossbearers, and crossties (the thinner lateral members between the crossbearers).

Other components of the gondola are also clearly visible including the brake reservoir, brake cylinder, and the entire foundation of the braking system. In order to determine the resolution of the panoramic images, engineering drawings were acquired from Norfolk Southern for each of the cars that were tested. By measuring the length of components in the panoramic image in pixels and dividing by the actual lengths of the components, the pixel-to-foot ratio (i.e. the image resolution) was determined to be 92.3 pixels per foot.

Figure 5: Locomotive repair pit used for data collection (a); camera and lighting set-up (b)

(a)

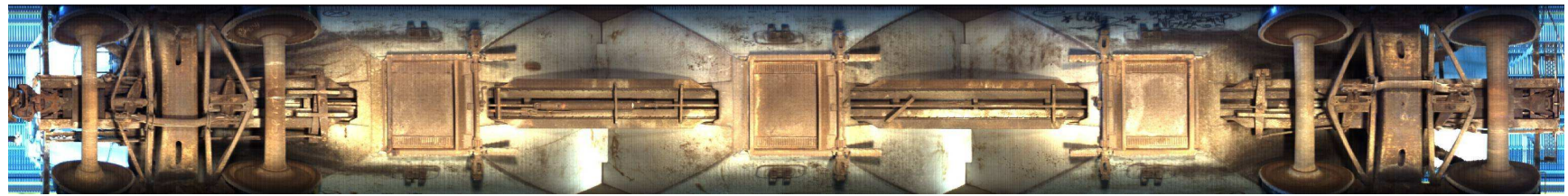

(b)

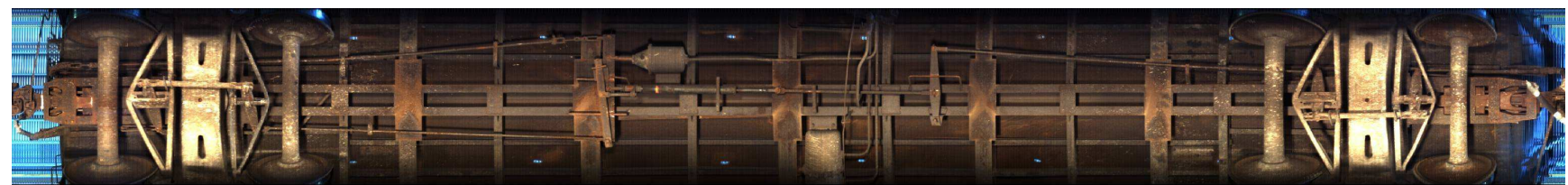

Figure 6: Panoramic images of hopper car (a) and gondola car (b) taken from NS locomotive repair facility in Decatur 


\section{DATA ANALYSIS}

Given a panoramic image of the car underbody, the algorithms must detect and localize the center sill and inspect it for two types of defects: (i) deformation, caused by bending and/or buckling and (ii) the presence of breaks or cracks. The need to minimize processing speed, as well as the nature of the two types of defects being considered, necessitates a multiscaleanalysis approach. The image area occupied by the center sill and the image region representing a crack differ significantly in size. As a result, the detection of the center sill requires analyzing large pixel neighborhoods; while the detection of breaks and cracks requires analyzing fineresolution image details. A computationally efficient strategy capable of addressing these two image-analysis extremes is known as multiscale image segmentation. This strategy provides access to pixel neighborhoods of varying size, which can be further used for detection and inspection of the center sill. The machine vision algorithm will consist of the following steps: First, parse the panoramic image into homogeneous-intensity regions at all degrees of inter-region versus intra-region homogeneity of pixel values present in the image; Second, analyze regions obtained at the coarsest scale (showing limited detail) to detect the center sill by using a known model (e.g. a rectangular shaped object located at the center of the panoramic image); Third, inspect the contours of the image regions occupied by the center sill to measure their deviation from the model, and thus the degree of the sill's bending and buckling; and Fourth, recursively analyze sub-regions embedded within the region representing the center sill to detect cracks or breaks in the center sill by using known models (e.g., a crack typically appears in the image as an elongated, dark region that represents a discontinuity in brightness of the center sill). This recursive analysis is feasible due to the multiscale image segmentation algorithm previously developed at
UIUC and noted in step one $[10,11,12]$. In this case, object detection immediately produces object segmentation since region boundaries generally coincide with boundaries of an object present in the image. That is, detection of the center sill in step two simultaneously delineates its boundaries, and thus localizes its position in the image. Similar to center sill detection, the identification of cracks and breaks in the center sill is based on known models of these defects. Identification of a crack or break simultaneously localizes its position, orientation, and length, and can be used to evaluate the magnitude of the discovered defect.

\subsection{Multiscale Image Segmentation}

The segmentation algorithm partitions the image into homogeneous regions of previously unknown shape, size, gray-level contrast, and topological context. A region is perceived to be homogeneous if variations in pixel intensity within the region are smaller than intensity variations of its surroundings, regardless of its absolute degree of variability. Consequently, image segmentation may be performed at a range of homogeneity values (Figure 7).

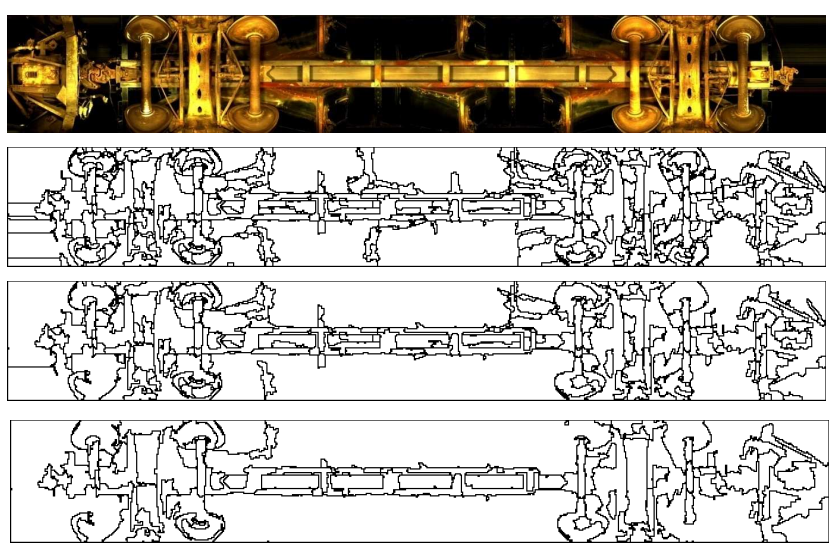

Figure 7: Multiscale segmentation hierarchy of the hopper car image showing the car underbody with the segmentation scale increasing from top to bottom

At any scale, recursive segmentation may be performed to extract finer scale segments characterized by an increasing degree of homogeneity. This process continues until one 
obtains strictly constant intensity regions, yielding a multiscale segmentation of the image. As the scale increases, smaller regions strictly merge to form a larger region, which means that the segmentation algorithm is hierarchical. The same multiscale segmentation algorithm can also be used for simultaneous inspection of other structural components in addition to the center sill. For example, analyzing the image segmentation at a finer scale than that used for center sill inspection, crossbearers can also be inspected for breaks, cracks, bending and buckling (Figure 8).

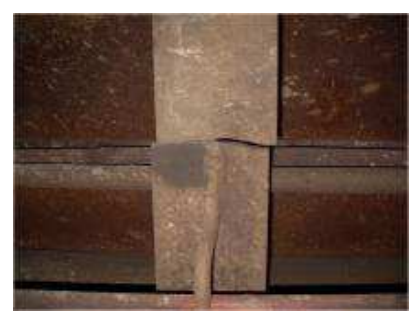

(a)

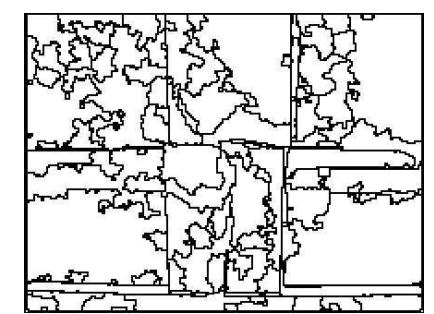

(b)
Figure 8: Digital picture of a broken crossbearer (a) with a fine-scale segmentation of the image (b)

\subsection{Center Sill Inspection}

All videos are taken from the same camera distance and viewpoint, so the train moves nearly parallel to one of the camera axes. This allows us to hypothesize that the center sill: (1) is centrally located in the corresponding panorama, (2) appears as a rectangle with possible embedded patterns within the rectangle, and (3) two longer edges of the rectangle lie along two image rows. Therefore, the center sill can be modeled as a large, rectangular-shaped object, prominently featured at the center of the panoramic image against the darker background. A template is developed based on the model parameters above or made from averaging templates created from panoramic images from cars of the same type. Then, starting with the coarsest levels of the segmentation hierarchy, the template is matched to the segmentation image to find the central location of the center sill between the wheel sets (Figure 9).

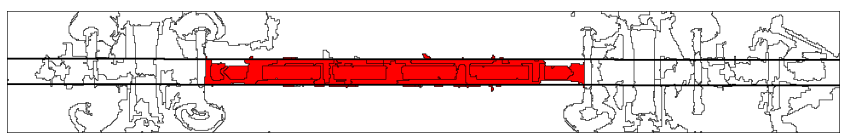

Figure 9: Center sill detection using the coarsest-scale segmentation

Once identified, the matching edges are interpreted as contours of the center sill. These identified edges are also taken as the general direction in which the center sill extends across the image. Given that the camera view is along the surface perpendicular to and directly below the center of the car, the known physical width of the center sill in the scene can be immediately mapped to the number of pixels associated with this width in the image. This mapping technique serves to calibrate the measurement of deformation of the center sill in the image. The average error of identified contours of the center sill using multiscale segmentation, is two pixels, which corresponds to only 0.26 inches. Improved camera resolution should reduce this error even further.

\subsection{Pixel Summation}

An alternative, less computationally intensive method could be used to find the central location of the center sill. This method, based on pixel summation, is carried out by summing the pixels longitudinally for each row of the segmented image (or edge image) of the car panorama. Along each row in the edge image (Figure 10a) we compute the number of pixels present (i.e., pixels belonging to longitudinal edge lines in the image). Prominent peaks in the histogram of the pixel summation denote long, straight sections in the image (Figure 11). Since the center sill creates the longest edges in the panoramic image, the two largest peaks (rows 276 and 388) correspond to the outer contours of the center sill, while the four interior peaks correspond to the inner contours of the center sill. The outer contours of the center sill are then denoted with parallel lines (Figure 10b). 
(a)



(b)

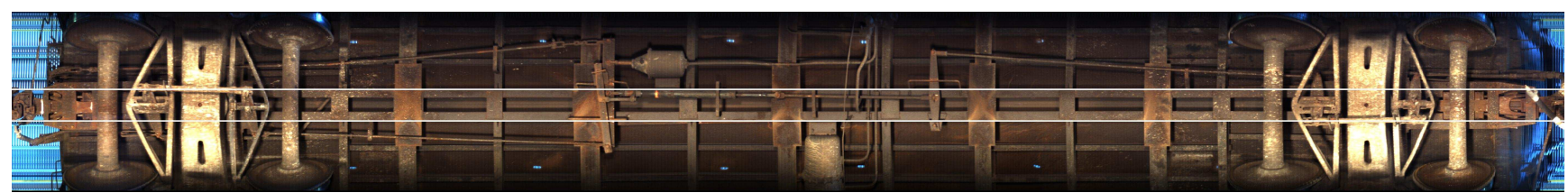

Figure 10: Edge image of gondola car underbody panorama (a) and original panorama with center sill detected (b)

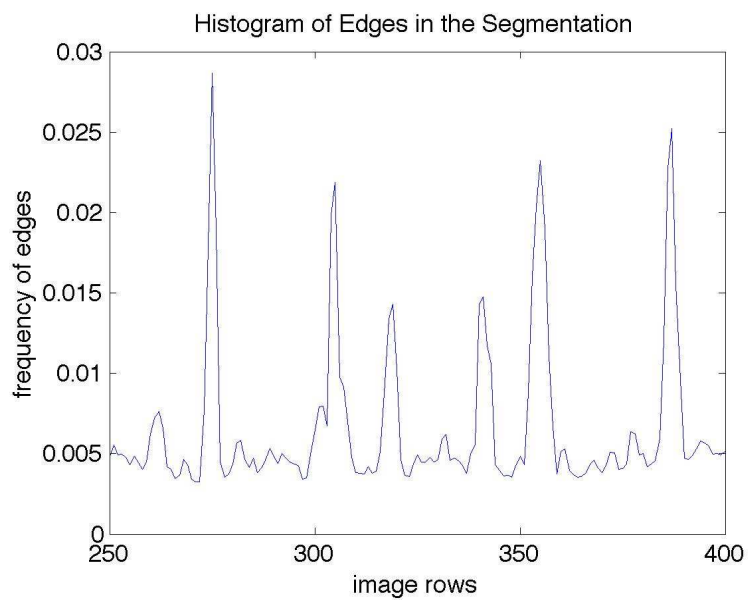

Figure 11: Histogram of the pixel summations belonging to region boundaries

These detected edges can then be used to guide the search for the remaining parts of the center sill as described in the previous method. Once the contours of the center sill are identified, they are compared with the ideal template. Any deviation from the parallel lines is interpreted as deformation. Note that this method can be applied in the lateral direction as well to identify and inspect crossbearers and crossties. In this way, pixel summation provides flexibility with reduced computational requirements. However, it does not provide the same level of accuracy or robustness as the multiscale segmentation approach when considering the constraints of the AISC system.

\section{$5.4 \quad$ Inspection of Cracks and Breaks}

The image region identified as the center sill will be analyzed to detect the presence of cracks and breaks. This phase of work is still in preliminary stages, but a multiscale process has been proposed as a potential approach to this aspect of inspection. Both cracks and breaks can be modeled as distinct objects that may occur in the image area occupied by the center sill. A crack can be modeled as a homogeneous, elongated region that appears darker than the center sill. Similarly, a break can be modeled as a dark region that represents a discontinuity in the following properties of the center sill: brightness, contiguity of the sill's contours, and co-linearity and parallelism with parts of the center sill's contours. To identify breaks and cracks, a multiscale strategy will be used that recursively searches smaller subregions embedded in the region occupied by the center sill, and contrasts them against models of breaks and cracks (Figure 12).

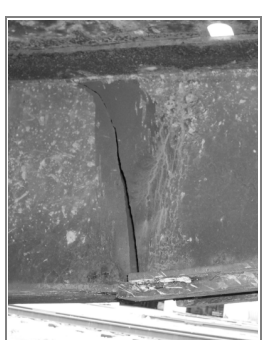

(a)



(b)

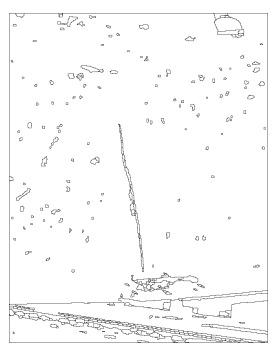

(c)
Figure 12: Original digital image of a crack (a), and fine to coarse segmentation images, from multiscale segmentation, showing good isolation of a crack to be identified (b) and (c)

If any of these subregions exhibit properties defined by the models, they will be considered as 
potential cracks or breaks. In addition to detection, we will also be able to identify the position, orientation, length and other characteristics of cracks and breaks and thus assess the degree of damage. Since cracks, in general, appear at finer resolutions of the image segmentation, their detection is expected to be more difficult than breaks; however, preliminary field data indicate that it will be feasible.

\section{DISCUSSION AND CONCLUSIONS}

Initial data collection and analysis has demonstrated the feasibility of AISC for the improvement of the effectiveness and efficiency of railcar underbody inspections. This study provides the basic system parameters needed to inspect and evaluate the health of railcar structural underbody components and provides several machine vision approaches for inspection and defect detection. As a result of this research, vendors have designed and implemented a field prototype and begun testing at mainline speeds. When complete, AISC will be capable of inspecting the undercarriage of an entire train, identifying areas of concern, reporting the suspected defects to qualified inspection personnel, and documenting the condition of structural components for the implementation of condition-based maintenance. AISC will also provide the basis for future machine vision systems capable of addressing other mechanical component problems visible from the bottom of the car (e.g. missing coupler pins, broken or missing coupler retaining pin bolts, and broken train line trolleys).

The ultimate goal for railcar inspection is a complete, automated inspection system that will inspect the entire car via a system of wayside cameras, including the AISC cameras located below the car. In this way, freight cars will be inspected more thoroughly and efficiently and the safety risks associated with manual car inspection will be minimized through the reduced exposure to potential yard hazards. Additionally, reducing inspection time will increase yard efficiency and improve overall network capacity by reducing the time needed to process inbound and outbound trains. By implementing machine vision technology and other automated inspection systems, North America's railroads will be poised to improve system-wide safety and efficiency through condition-based maintenance strategies and reduced network costs associated with the current inspection process.

\section{ACKNOWLEDGEMENTS}

This research was sponsored by a grant from the AAR's Strategic Research Initiative Program. The authors thank Semih Kalay, Jim Robeda and Charles Powell at TTCI and members of the TDTI committee for providing technical guidance for this project. Thanks to Gary Nelson, Chuck Sloan and others at Norfolk Southern and Darrell Iler, John Geary, and others at $\mathrm{CN}$ for providing mechanical inspection expertise and for the use of their facilities. Car inspection data were provided by FRA and Railinc. The authors are also grateful to Tim Crouch, Jon Roma, and others at the Monticello Railway Museum for use of their facilities and equipment. Esther Resendiz and Emre Akbas from the Computer Vision and Robotics Laboratory of the Beckman Institute developed panoramic and crack segmentation images, and Mike Wnek and Brennan Caughron in the Railroad Engineering Program at UIUC provided photographs, diagrams and assistance during field testing. J. Riley Edwards has been supported in part by grants to the UIUC Railroad Engineering Program from CN, CSX, Hanson Professional Services, Norfolk Southern and the George Krambles Transportation Scholarship Fund. 
8. REFERENCES

(1) Kratville, W.W. ed. The Car and Locomotive Cyclopedia of American Practices. $6^{\text {th }}$ ed, Simmons-Boardman Books, Inc. Omaha, 1997.

(2) U.S. Department of Transportation, Federal Railroad Administration, Office of Safety, Code of Federal Regulations Title 49. Railroad Freight Car Safety Standards Part215. November 1, 2007.

(3) Robeda, J. and S. Kalay. Technology drives US train inspections. International Railway Journal, May, 2008. http://findarticles.com/p/articles/mi_m0BQ Q/is_5_48/. Accessed July 19, 2008.

(4) Hart, J. M. et al. A Machine Vision System for Monitoring Railcar Health: Preliminary Results. Technology Digest: TD-04-008. Association of American Railroads, Pueblo, Colorado, 2004.

(5) Edwards, J. R. et al. Development of Machine Vision Technology for Railcar Safety Appliance Inspection. Proceedings of the International Heavy Haul Conference Specialist Technical Session - High Tech in Heavy Haul, Kiruna, Sweden, 2007, pp. 745-752.

(6) Hart, J. M. et al. Machine Vision Using Multi-Spectral Imaging for Undercarriage Inspection of Railroad Equipment. In Proceedings of the $8^{\text {th }}$ World Congress on Railway Research, Seoul, Korea, 2008.

(7) Lagnebäck, R. Evaluation of wayside condition monitoring technologies for condition-based maintenance of railway vehicles, Licentiate Thesis, Luleå University of Technology, Luleå, Sweden, 2007.
(8) Ouyang, Y. et al. Optimal Locations of Railroad Wayside Defect Detection Installations. CAC\&IE, University of Illinois, 2008.

(9) U.S. Department of Transportation, Federal Railroad Administration. Motive Power and Equipment Compliance Manual. Chapter 4, Page 22. http://www.fra.dot.gov/us/content/1248. Accessed on July 25, 2008.

(10) Ahuja, N. A transform for multiscale image segmentation by integrated edge and region detection. IEEE TPAMI, vol. 18, no. 12, pp. 1211-1235, 1996.

(11) Tabb, M. and N. Ahuja. Multiscale image segmentation by integrated edge and region detection. IEEE Trans. Image Processing, vol. 6, no. 5, pp. 642-655, 1997.

(12) Arora H. and N. Ahuja. Analysis of ramp discontinuity model for multiscale image segmentation. ICPR, vol. 4, 2006, pp. 99103. 